\title{
Beyond a Fluorescent Probe: Inhibition of Cell Division Protein FtsZ by mant-GTP Elucidated by NMR and Biochemical Approaches
}

\author{
Sonia Huecas, ${ }^{\dagger, \|}$ Filipa Marcelo, ${ }^{\dagger, \ddagger}, \|$ Almudena Perona, ${ }^{\S, \perp}$ Laura B. Ruiz-Ávila, ${ }^{\dagger, \#}$ Antonio Morreale, ${ }^{\S, \nabla}$
} F. Javier Cañada, ${ }^{\dagger}$ Jesús Jiménez-Barbero, ${ }^{*}, \dagger, \bigcirc$ and José M. Andreu* ${ }^{\dagger}$

${ }^{\dagger}$ Centro de Investigaciones Biológicas, CIB-CSIC, Ramiro de Maeztu 9, 28040 Madrid, Spain

${ }^{\ddagger}$ UCIBIO, REQUIMTE, Dept. de Química, Faculdade de Ciências e Tecnologia, UNL, 2829-516 Caparica, Portugal

${ }^{\S}$ Unidad de Bioinformática, Centro de Biología Molecular Severo Ochoa, CBMSO-CSIC, Cantoblanco, 28049 Madrid, Spain

\section{Supporting Information}

ABSTRACT: FtsZ is the organizer of cell division in most bacteria and a target in the quest for new antibiotics. FtsZ is a tubulin-like GTPase, in which the active site is completed at the interface with the next subunit in an assembled FtsZ filament. Fluorescent mant-GTP has been extensively used for competitive binding studies of nucleotide analogs and synthetic GTPreplacing inhibitors possessing antibacterial activity. However, its mode of binding and whether the mant tag interferes with FtsZ assembly function were unknown. Mant-GTP exists in equilibrium as a mixture of $\mathrm{C}^{\prime}$ - and C3'-substituted isomers. We have unraveled the molecular recognition process of mant-GTP by FtsZ monomers. Both isomers bind in the anti glycosidic bond conformation: $2^{\prime}$-mant-GTP in two ribose puckering conformations and $3^{\prime}$-mant-GTP in the preferred $\mathrm{C}_{2}^{\prime}$ endo conformation. In each case, the mant tag strongly interacts with FtsZ at an extension of the

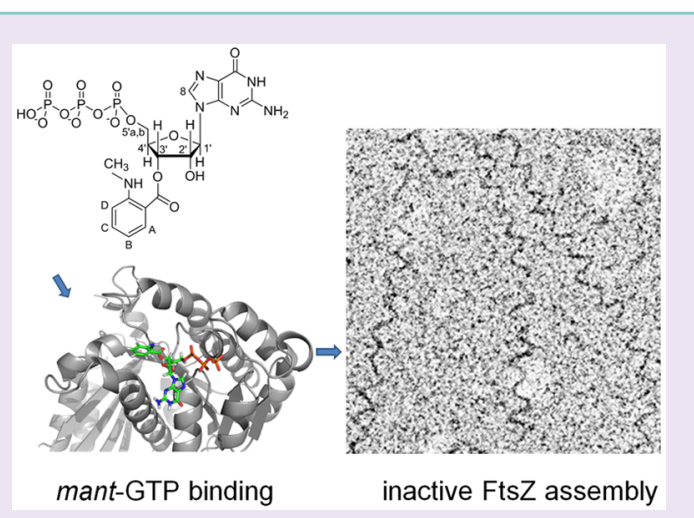
GTP binding site, which is also supported by molecular dynamics simulations. Importantly, mant-GTP binding induces archaeal FtsZ polymerization into inactive curved filaments that cannot hydrolyze the nucleotide, rather than straight GTP-hydrolyzing assemblies, and also inhibits normal assembly of FtsZ from the Gram-negative bacterium Escherichia coli but is hydrolyzed by FtsZ from Gram-positive Bacillus subtilis. Thus, the specific interactions provided by the fluorescent mant tag indicate a new way to search for synthetic FtsZ inhibitors that selectively suppress the cell division of bacterial pathogens.

$\mathrm{F}$ luorescent nucleotides are widely employed in the biosciences due to their ease of use and detection sensitivity. ${ }^{1}$ However, the added fluorescent tags can modify molecular recognition or enzymatic activity with respect to the natural nucleotide. Fluorescent mant-GTP $\left(2^{\prime} / 3^{\prime}-\mathrm{O}-(\mathrm{N}\right.$-methyl-anthraniloyl)-guanosine- $5^{\prime}$-triphosphate $)^{2,3}$ has been used as a chemical probe to investigate GTP-binding proteins over three decades. Functional studies have shown that mant-GTP is hydrolyzed similarly to GTP by $21^{\text {NRAS } 4}$, is also hydrolyzed by $\mathrm{G}_{0}$ protein, ${ }^{5}$ and is processed to mant-cGMP by the nitric oxide receptor guanylyl cyclase, ${ }^{6}$ but the mant tag inhibits membrane adenylyl cyclase ${ }^{7,8}$ and alters the kinetics of nucleotide hydrolysis and exchange by small GTPases. ${ }^{9}$ On the other hand, mant-GTP was reported to promote tubulin assembly into microtubules in a similar fashion as GTP. ${ }^{10}$ However, detailed structural information on bound mant-GTP is scarce. $^{7,8,11,12}$ In addition, the commonly employed mantGTP is a mixture of $2^{\prime}$ - and $3^{\prime}$-substituted isomers (Figure 1A) in slow equilibrium via acyl migration. ${ }^{3}$

The essential cell division protein FtsZ assembles into the $\mathrm{Z}$ ring that determines the division plane and recruits the remainder of the cytokinetic machinery in most bacteria. ${ }^{13,14}$ FtsZ is a structural homologue of eukaryotic tubulin, and both are distinct GTPases whose interfacial active site is formed by the association of consecutive monomers, upon assembly into similar polar protofilaments. ${ }^{15}$ GTP binding is required for assembly, and its hydrolysis to GDP triggers disassembly, giving rise to microtubule dynamic instability ${ }^{16}$ and FtsZ polymer dynamics. ${ }^{17}$ Due to its central role and ubiquity, FtsZ is an attractive target for the discovery of new antibacterial agents, ${ }^{18-24}$ which are urgently needed to fill the gap in antibiotic discovery and to counter the spread of antibioticresistant pathogens. ${ }^{25}$ In this context, we employed mant-GTP to probe the kinetics and energetics of FtsZ-nucleotide interactions $^{26}$ and established a competitive assay using the fluorescence polarization of bound mant-GTP to determine inhibitor binding to the FtsZ nucleotide-binding site. ${ }^{27}$ We have also employed this mant fluorophore-based assay to investigate the mechanism of C-8 substituted nucleotide FtsZ inhibitors $^{28,29}$ and to identify new GTP-replacing inhibitors of bacterial cell division that are active on resistant pathogens. ${ }^{30-32}$ Remarkably, the $2^{\prime} / 3^{\prime}$-mant-GTP isomer mixture behaved as a single ligand species in these studies.

Received: June 10, 2015

Accepted: August 6, 2015

Published: August 6, 2015 


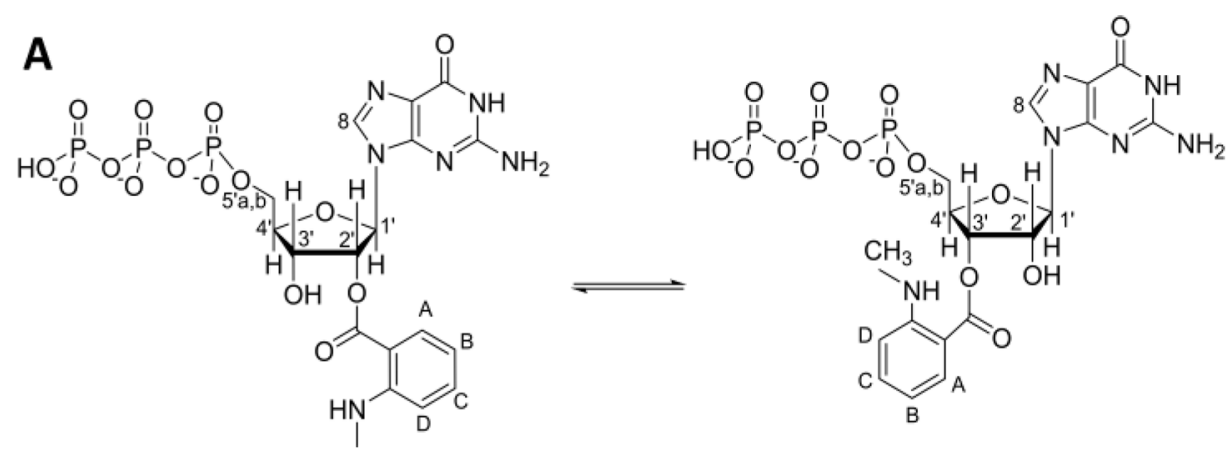

3' mant-GTP

B

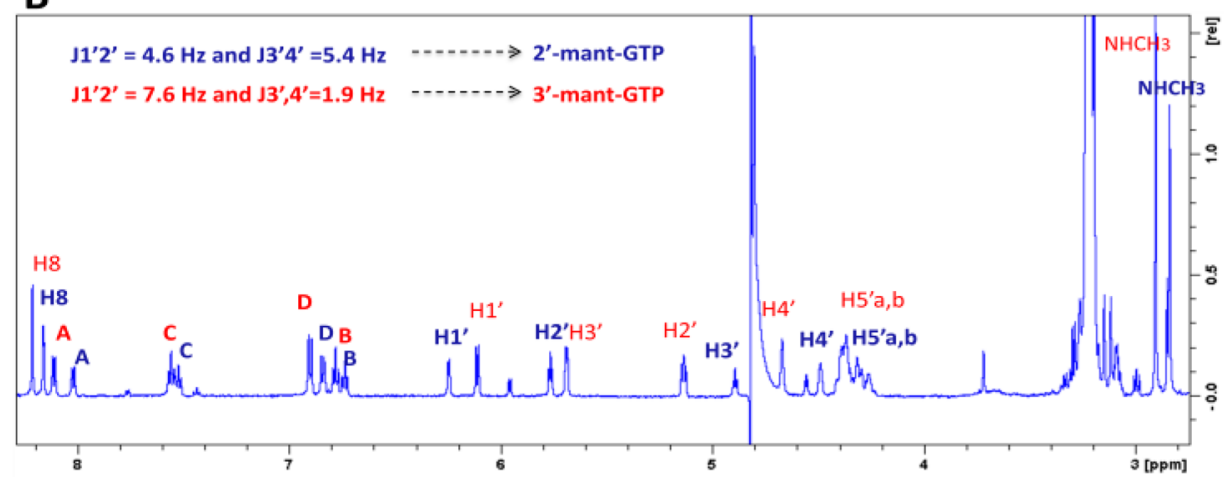

Figure 1. (A) Structures of 2' mant-GTP and $3^{\prime}$-mant-GTP isomers and proton numbering used in the NMR analysis. (B) ${ }^{1} \mathrm{H}$ NMR spectrum of $2^{\prime} /$ $3^{\prime}$-mant-GTP recorded at $600 \mathrm{MHz}$ and $298 \mathrm{~K}$. The resonances from each isomer are resolved as indicated by blue labels for $2^{\prime}$ - and red labels for $3^{\prime}$ mant-GTP. See also Figure S1. The ribose conformation may be deduced by measuring the vicinal H/H coupling constants $(J)$, particularly $J_{1^{\prime} 2^{\prime}}$ and $J_{3^{\prime}, 4^{\prime}}$, as well as the proton-proton NOEs within the ribose ring and those between the ribose ring and $\mathrm{H} 8$ of the guanine base. Small $J_{1^{\prime}, 2^{\prime}}$ values $(<3$ $\mathrm{Hz}$ ) are characteristic of a predominant $\mathrm{C}^{\prime}$ endo form, whereas medium-large $J_{1^{\prime} 2^{\prime}}$ values (ca. $7 \mathrm{~Hz}$ ) correspond to major $\mathrm{C}^{\prime}$ endo ribose conformations. Additionally, $J_{1^{\prime}, 2^{\prime}}$ and $J_{3^{\prime}, 4^{\prime}}$ are expected to be strongly anticorrelated. $J$-coupling inspection of the GTP ${ }^{1} \mathrm{H} \mathrm{NMR} \mathrm{spectrum}\left(J_{1^{\prime}, 2^{\prime}}=5.8\right.$ $\mathrm{Hz}$ and $J_{3^{\prime}, 4^{\prime}}=3.7 \mathrm{~Hz}$ ) thus revealed that GTP adopts both $\mathrm{C} 2^{\prime}$ endo $(75 \%)$ and $\mathrm{C}^{\prime}$ endo $(25 \%)$ conformations in solution. ${ }^{29}$ Similarly, for $2^{\prime}$ mantGTP $\left(J_{1^{\prime} 2^{\prime}}=4.6 \mathrm{~Hz}\right.$ and $\left.J_{3^{\prime} 4^{\prime}}=5.4 \mathrm{~Hz}\right)$ there is an equilibrium between the $\mathrm{C}^{\prime}$ endo and $\mathrm{C}^{\prime}$ endo ribose conformations at a 50:50 ratio, whereas for $3^{\prime}$ mant-GTP the coupling constants $\left(J_{1^{\prime} 2^{\prime}}=7.6 \mathrm{~Hz}\right.$ and $\left.J_{3^{\prime}, 4^{\prime}}=1.9 \mathrm{~Hz}\right)$ clearly indicate a strong preference for the $\mathrm{C}^{\prime}$ endo geometry.

However, the mode of $2^{\prime} / 3^{\prime}$-mant-GTP binding to FtsZ has remained obscure. Key questions include whether one or both regioisomers bind to FtsZ, the ligand bound conformation and identification of the binding epitope, and how the bulky mant group is accommodated in the GTP binding site. While addressing these questions, we have also found that mant-GTP bound at the association interface between monomers drastically interferes with FtsZ assembly. The results indicate that the specific interactions made between the mant group and the GTP binding domain may be exploited to design new antibacterial FtsZ inhibitors.

\section{RESULTS AND DISCUSSION}

Conformational Analysis of 2'- and 3'-mant-GTP Nucleotides in Solution. The conformation of nucleotides can be generally defined by three key structural features: the ribose puckering ( $\mathrm{C}^{\prime}$ endo vs $\mathrm{C}^{\prime}$ endo), the glycosidic torsion angle (anti-type vs syn-type), and the exocyclic $\mathrm{C}^{\prime}-$ $\mathrm{C5}^{\prime}$ bond orientation ${ }^{33}$ (Supporting Information Figure $\mathrm{S} 1 \mathrm{~A}, \mathrm{~B})$. NMR analysis of the vicinal $\mathrm{H} / \mathrm{H}$ coupling constants $(J),{ }^{29}$ especially $J_{1^{\prime} 2^{\prime}}$ and $J_{3^{\prime} 4}$ (Figure 1 ), indicated that $2^{\prime}$-mant$\operatorname{GTP}\left(J_{1^{\prime} 2^{\prime}}=4.6 \mathrm{~Hz}\right.$ and $\left.J_{3^{\prime} 4^{\prime}}=5.4 \mathrm{~Hz}\right)$ is in equilibrium between the $\mathrm{C} 2^{\prime}$ endo and $\mathrm{C} 3^{\prime}$ endo ribose conformations at a 50:50 ratio, whereas $3^{\prime}$-mant-GTP $\left(J_{1^{\prime} 2^{\prime}}=7.6 \mathrm{~Hz}\right.$ and $J_{3^{\prime} 4^{\prime}}=1.9$ $\mathrm{Hz}$ ) has a strong preference for the $\mathrm{C} 2$ ' endo geometry. The NOE pattern between the guanine $\mathrm{H} 8$ and the ribose protons has proven useful to determine the type of conformation around the glycosidic linkage. ${ }^{34}$ Thus, the presence of strong NOE contacts between the ribose $\mathrm{H} 2^{\prime}$ and/or $\mathrm{H}^{\prime}$ with guanine $\mathrm{H} 8$ strongly suggests a predominant anti geometry, whereas strong $\mathrm{H}^{\prime}-\mathrm{H} 8 \mathrm{NOE}$ cross-peaks are indicative of a major syn conformation (Figure S1C). The structural information was obtained from a NOESY experiment (Figure 2A), which indicated that both $2^{\prime}$ - and $3^{\prime}$-mant-GTP were present predominantly in the anti-type conformation, as nonsubstituted GTP. ${ }^{29} 2^{\prime}$-mant-GTP presents a medium H8$\mathrm{H} 2^{\prime}$ and a weak $\mathrm{H} 8-\mathrm{H}^{\prime}$ ' NOE contact on the spectrum, whereas $3^{\prime}$-mant-GTP presents only a strong NOE contact between $\mathrm{H} 8$ and $\mathrm{H}_{2}{ }^{\prime}$. Nevertheless, for $2^{\prime}$-mant-GTP, a small contribution of the syn conformer was detected (weak $\mathrm{H}^{\prime}{ }^{\prime}-\mathrm{H} 8$ NOE). The relative intensities of $\mathrm{H} 8-\mathrm{H} 2^{\prime}$ and $\mathrm{H} 8-\mathrm{H} 3^{\prime}$ NOEs in $2^{\prime}$-mant-GTP correlate with the significant proportion of $\mathrm{C}^{\prime}$ endo geometry (Figure S1C), which is consistent with the $J$ coupling values. For $3^{\prime}$-mant-GTP, the $\mathrm{H} 8-\mathrm{H} 2^{\prime}$ NOE crosspeak confirms a major $\mathrm{C}^{\prime}$ endo ribose conformation in solution. No NOE contacts were observed between the fluorescent tag and ribose or guanine protons. In summary, from the NOE and J-coupling data, it was possible to deduce distinct conformers for $2^{\prime}$ - and $3^{\prime}$-mant-GTP; nonconstrained molecular mechanics conformational analysis indicated two major local minima for the $2^{\prime}$-mant-GTP isomer in the $\mathrm{C}^{\prime}$ endo and $\mathrm{C}^{\prime}$ endo conformations and one major local 

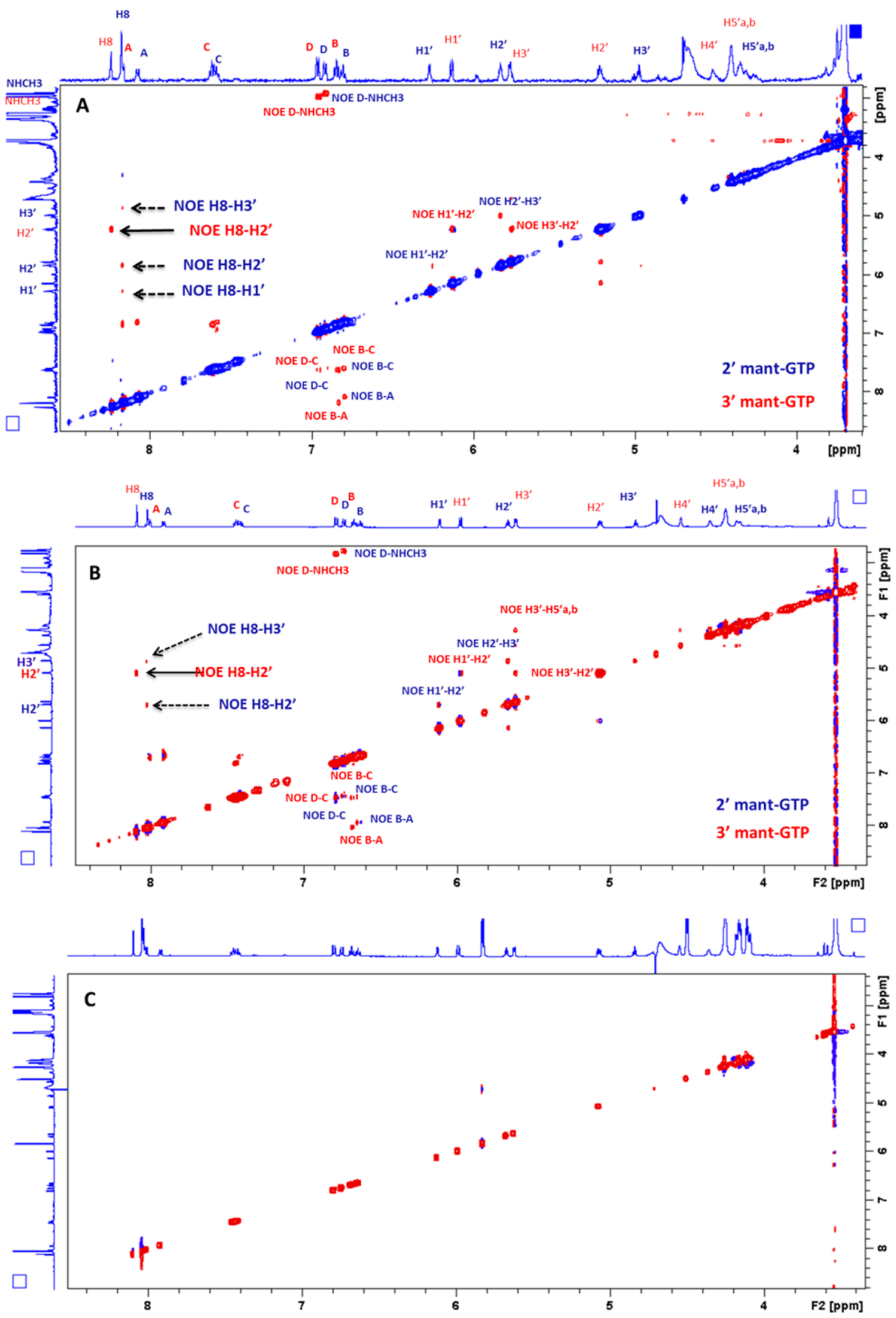

Figure 2. (A) NOESY spectrum of $2^{\prime} / 3^{\prime}$-mant-GTP recorded at $313 \mathrm{~K}$ (at $298 \mathrm{~K}$ and $600 \mathrm{MHz}$, the cross-peaks observed were close to the zero NOE). $2^{\prime}$-mant-GTP isomer signals are indicated by blue labels and $3^{\prime}$-mant-GTP isomer signals by red labels, throughout this study. (B) tr-NOESY spectrum $(298 \mathrm{~K}, 100 \mathrm{~ms}$ mixing time $)$ of $2^{\prime} / 3^{\prime}$ - mant-GTP $(600 \mu \mathrm{M})$ in the presence of FtsZ $(30 \mu \mathrm{M})$. (C) Same as B plus GTP (2.4 mM) to displace mant-GTP binding. Note that tr-NOEs from nonsubstituted GTP are not detected due to its slow dissociation on the NMR relaxation time scale. $^{29}$ 
minimum for $3^{\prime}$-mant-GTP in the $\mathrm{C}^{\prime}$ endo conformation, which account for the NMR experimental data and were selected to represent the main conformations present in solution (Figure S1D-G). Indeed, Molecular Dynamics (MD) simulations supported $\mathrm{C}^{\prime}$ endo and $\mathrm{C}^{\prime}$ endo conformations of $2^{\prime}$-mant-GTP and the preference of $3^{\prime}$-mant-GTP for the $\mathrm{C} 2{ }^{\prime}$ endo pucker observed by NMR (Figure S2).

Conformation of FtsZ-bound $2^{\prime}$ and $3^{\prime}$ mant-GTP. A tr-NOESY Analysis. Nucleotide devoid FtsZ from the thermophilic archaea Methanococcus jannaschii (Mj-FtsZ) has proven to be a robust model for NMR ligand binding studies of the conserved nucleotide binding site of unassembled FtsZ monomers. ${ }^{29}$ Previous biochemical results were compatible with Mj-FtsZ binding both 2 '- and 3'-mant-GTP isomers at a similar rate. ${ }^{26}$ We measured the binding equilibrium of mantGTP to apo-FtsZ in the Tris- $\mathrm{D}_{2} \mathrm{O}$ buffer used for NMR experiments, compared to Tris- $\mathrm{H}_{2} \mathrm{O}$ buffer, with fluorescence anisotropy titrations. ${ }^{27}$ These results showed that $\mathrm{D}_{2} \mathrm{O}$ does not modify mant-GTP binding; the data were fitted by model binding isotherms with a single equilibrium binding constant $K_{\mathrm{b}}$ $=4 \times 10^{5} \mathrm{M}^{-1}$ (Figure S3A), indicating that both $2^{\prime}$ - and $3^{\prime}$ mant-GTP isomers bind to $\mathrm{Mj}$-FtsZ with similar affinities weaker than GTP affinity $\left(\right.$ ca. $\left.1 \times 10^{8} \mathrm{M}^{-1}\right){ }^{27}$

NMR tr-NOESY provides an adequate means to determine the conformation of bound ligands. ${ }^{35,36}$ For the NMR experiments of mant-GTP binding to unassembled $\mathrm{Mj}$-FtsZ, to avoid any interference from FtsZ self-association, we used Tris- $\mathrm{D}_{2} \mathrm{O}$ buffer without magnesium at $298 \mathrm{~K}$ (Figure S3B). In contrast to the null cross-peaks of the free ligand at $298 \mathrm{~K}$, in trNOESY experiments, strong negative NOEs were detected for both $2^{\prime}$ - and $3^{\prime}$-mant-GTP isomers in the presence of Mj-FtsZ (Figure 2B), which indicates that the protein binds both isomers in a similar fashion. The time scale of the NMR measurements is too fast to allow interconversion (the isomer re-equilibration half time is $7 \mathrm{~min}$ at $\mathrm{pH} 7 \cdot 4^{3}$ ). To evaluate mant-GTP binding specificity, we repeated the mant-GTP-FtsZ tr-NOESY in the presence of GTP. According to the relative affinities of GTP and mant-GTP binding to Mj-FtsZ, GTP is expected to suppress mant-GTP binding to the nucleotide site. All of the negative cross-peaks of mant-GTP isomers disappeared from the tr-NOESY spectrum upon the addition of GTP (Figure 2C). This result indicates that the tr-NOEs of 2 - and $3^{\prime}$-mant-GTP arise from the specific interaction with the Mj-FtsZ GTP-nucleotide binding site. A complete displacement of mant-GTP binding to FtsZ by GTP was also observed by fluorescence anisotropy at probe concentrations 3 orders of magnitude lower ${ }^{26,27}$ than in the NMR experiments.

The anti and syn population distribution in the bound state was estimated by evaluating the intensities of the $\mathrm{H} 8-\mathrm{H} 2$ ', $\mathrm{H} 8-\mathrm{H}^{\prime}$, and $\mathrm{H} 8-\mathrm{H} 3^{\prime}$ crosspeaks (Figure $\mathrm{S} 1 \mathrm{~B}$ ). The presence of the $\mathrm{H} 8-\mathrm{H} 2^{\prime} \mathrm{NOE}$ contact with the concomitant absence of the $\mathrm{H} 8-\mathrm{H}^{\prime}{ }^{\prime}$ NOE cross-peak (Figure 2B) indicates that both $2^{\prime}$ - and $3^{\prime}$-mant-GTP adopt a similar anti-type geometry as the bioactive conformation. Mj-FtsZ thus selectively recognizes the major anti-type conformation of mant-GTP isomers present in solution, similarly to the unmodified guanine nucleotide, ${ }^{29}$ rather than the minor syn-type $2^{\prime}$-mant-GTP conformation detected in the free probe. Regarding the puckering of the ribose ring, extensive line broadening effects prevented extracting nonambiguous structural information by coupling analysis at several mant-GTP/FtsZ molar ratios (3:1, 9:1, and 12:1). However, the relative intensities of the $\mathrm{H} 8-\mathrm{H} 2^{\prime}$ and $\mathrm{H} 8-\mathrm{H}_{3}{ }^{\prime}$ NOEs correlate with the proportion of $\mathrm{C}^{\prime}$ endo and
$\mathrm{C} 3^{\prime}$ endo geometries analyzed above (Figure S1C). The similar relative intensities found in the bound and free states indicate that identical ribose puckering conformations present in solution for each mant-GTP isomer are recognized by $\mathrm{Mj}$ FtsZ. Thus, FtsZ nonselectively binds $2^{\prime}$-mant-GTP in both $\mathrm{C} 2^{\prime}$ endo and $\mathrm{C} 3^{\prime}$ endo conformations, and $3^{\prime}$-mant-GTP in the preferred $\mathrm{C} 2$ ' endo conformation, in contrast with the single C3' endo conformation of GTP that is selectively bound by this protein. ${ }^{29}$ The presence of the mant substituent at either the $2^{\prime}$ or $3^{\prime}$ positions markedly modifies the conformational behavior of the furanose moiety. Finally, no additional NOE contacts between the nucleotide and the fluorescent tag protons of mant-GTP were detected in the bound state.

Binding Epitopes of 2 '- and $3^{\prime}$-mant-GTP Determined by STD Experiments. The binding modes of the $2^{\prime}$ - and $3^{\prime}$ mant-GTP isomers to the FtsZ nucleotide binding site were also analyzed using STD-NMR ${ }^{35}$ competition binding experiments. This method is highly convenient to determine whether two different ligands bind to the same site, distinguishing competitive from noncompetitive binding. ${ }^{37,38}$ STD competition experiments were thus performed with mant-GTP and MjFtsZ in the presence of GTP at different concentrations, to assess the binding specificity. We observed a partial decrease in STD proton signals of $2^{\prime}$ - and $3^{\prime}$-mant-GTP upon the gradual addition of GTP (Figure 3A and B). The initial decrease in the STD intensity is compatible with competition for the same binding site. However, signals remained in the STD spectra that corresponded to the ribose/guanine and aromatic mant protons. In GTP excess, ca. $42 \%$ of the ribose and $55 \%$ of the aromatic proton STD signal remained in the STD spectra.

These results indicate that under our STD-NMR conditions at high concentrations ( $0.6 \mathrm{mM}$ mant-GTP, $30 \mu \mathrm{M}$ FtsZ). different interactions between mant-GTP and FtsZ can be detected. Mant-GTP exhibits specific binding to the GTP site, in addition to nonspecific interactions (Figure S4). Figure 3C shows the specific STD intensities obtained by subtracting the remaining nonspecific STD intensities at a 4:1 GTP/mant-GTP ratio from the total STD intensities in the absence of GTP. The larger saturation signals arise from ribose $\mathrm{H1}^{\prime}$, followed by the aromatic mant protons, indicating a significant specific interaction between the fluorescent tag and the FtsZ binding site. The epitope mapping for $2^{\prime}$ - and $3^{\prime}$-mant-GTP is similar. The major difference between the isomers is the higher percentage of the STD for H8 in $2^{\prime}$ - compared to $3^{\prime}$-mantGTP. These results point out specific binding of the covalently attached mant tag to the GTP binding domain of the protein. We attribute the additional nonspecific STD intensities to transient low-affinity adsorption of mant-GTP at the protein surface, irrespective of its conformation, which was not picked up by the less sensitive conformation-detecting tr-NOESY experiments. STD is a highly sensitive method that can detect weak interaction events even in the millimolar affinity range.

Insights from FtsZ-mant-GTP Model Complexes. The NMR results contain key structural information that defines the bioactive conformations and epitopes of both the 2'- and 3'mant-GTP isomers when bound to FtsZ monomers. Therefore, to obtain insights into the binding mode of each isomer in the FtsZ nucleotide site, we employed computational methods to provide detailed models of the Mj-FtsZ-mant-GTP complexes. Representative conformers of each isomer, obtained from MD simulations in water, were substituted for GTP in the crystal structure of $\mathrm{Mj}$-FtsZ; the protein complexes were then subjected to $\mathrm{MD}$ simulations. The protein and ligand root- 

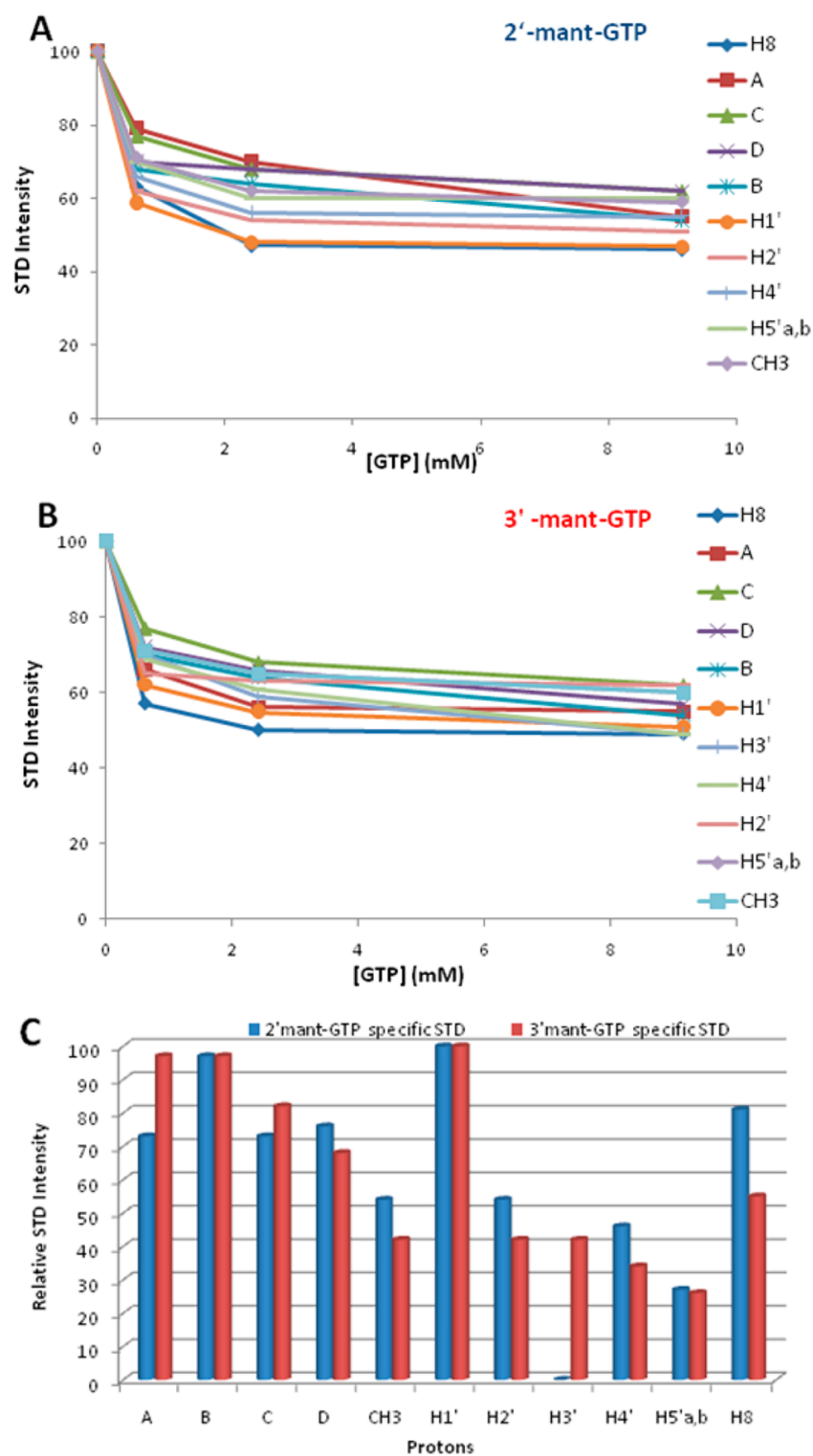

Figure 3. STD NMR competition experiment of mant-GTP $(0.6 \mathrm{mM})$ and Mj-FtsZ $(30 \mu \mathrm{M})$ with GTP. (A) Changes in STD proton signal intensities of $2^{\prime}$-mant-GTP upon the addition of increasing concentrations of GTP (except for the H3' STD signal that is close to the HDO water signal and could not be measured). (B) STD intensities of $3^{\prime}$-mant-GTP upon the addition of GTP. The H5'a,b STD signals were not resolved for any of both isomers. (C) Graphical epitope map (relative specific STD intensity) of $2^{\prime}$ - and $3^{\prime}$-mant-GTP, obtained by normalizing the STD intensities that were suppressed by GTP with respect to the highest STD response.

mean-square deviations (RMSD) from the initial coordinates were stabilized during the first portion of the $\mathrm{MD}$ trajectories (Figure S5A,B). The ligand and binding site exhibited flexibility, and the mant group switched between different rotational states (see Supporting Information Movies M1-M3). Representative complex structures that were compatible with the NMR results were observed during these independently performed $\mathrm{MD}$ simulations (Figure 4).

Mj-FtsZ accommodates the mant substituent opening a cavity (Figure S5C) between the ribose recognition loop T5 and helix H5, loop T6, and the N-terminal portion of helix $\mathrm{H} 7$ that bind the base. mant-GTP thus binds into a tripartite site that lodges the triphosphate, the guanine, and the mant moieties extending from the ribose scaffold (Figure 4A-C), although each $2^{\prime}$ and $3^{\prime}$ isomer adopts a different geometry (Figure S5D). Of note, the mant group overlaps with the position of naphthalene or biphenyl cores of synthetic GTPreplacing FtsZ inhibitors (Figure S5E). ${ }^{30,32}$ Compared to nonsubstituted GTP, the ribose and guanine rings are displaced toward the phosphate-binding region, particularly in the $\mathrm{C}^{\prime}$ endo ribose conformers. The nucleotide contacting structural elements undergo displacements to accommodate mant-GTP (Figure 4A-C). Interestingly, the aromatic mant group disables a $\pi$-stacking interaction between conserved FtsZ residues Phe 162 (loop T5) and Phe 208 (helix 7; Figure 4E-H), among other interactions made by mant-GTP (Figure S6). The nucleotide site of FtsZ monomers thus exhibits considerable plasticity, ${ }^{27}$ demonstrating the ability to bind synthetic inhibitors, ${ }^{30,32}$ GTP analogs substituted at C8 in the guanine ring, $^{28,29}$ and the mant derivatives at the ribose $\mathrm{O}^{\prime}$ and $\mathrm{O}^{\prime}$ positions described herein.

Because the nucleotide binding site becomes part of the longitudinal association interface between monomers in FtsZ filaments, ${ }^{20,39}$ we questioned whether the introduction of the mant group at this interface would affect the key proteinprotein interactions necessary for correct FtsZ assembly. Although both Mj-FtsZ and a narrow bacterial FtsZ interface may accommodate mant-GTP without steric clashes (Figure 4D), the introduction of the mant group and opening its binding cavity in the monomer may be expected to remodel the association interface with the next monomer and therefore to affect the structural dynamics of a FtsZ filament. We note that in the crystal structure of a discontinuous filament-like Mj-FtsZ dimer, ${ }^{39}$ the lower (minus-end) monomer uses loops H7-H6, T3, and T5, among other elements, to contact the upper (plusend) monomer. The movement of these elements to accommodate the mant group in the lower monomer (Figure $4 \mathrm{~A}-\mathrm{C}$ ) should thus modify its association with the upper monomer. However, the available Mj-FtsZ dimer structure is thought to present an open prehydrolysis interface that might close later, ${ }^{39}$ rather than a true continuous Mj-FtsZ filament, preventing its use for meaningful $\mathrm{MD}$ simulations of the mantGTP-induced modifications of the Mj-FtsZ association interface and filament structure.

Binding of mant-GTP Induces Polymerization of Archaeal FtsZ into Inactive Curved Filaments. The results described above prompted experimental analysis of how the additional mant group affects FtsZ assembly. Mant-GTP in the presence of magnesium is known to induce nucleated Mj-FtsZ polymerization at $55{ }^{\circ} \mathrm{C}$, above a critical protein concentration $\left(C_{\mathrm{r}}\right)$ similar to that of GTP-induced assembly, although without nucleotide hydrolysis. ${ }^{26}$ In fact, we confirmed that mant-GTP is not significantly hydrolyzed by Mj-FtsZ polymers (mantGTPase rate, $0.02 \pm 0.01 \mathrm{~min}^{-1}$; GTPase rate, $2.15 \pm 0.05$ min $^{-1}$ determined in Mes- $\mathrm{H}_{2} \mathrm{O}$ buffer at $55{ }^{\circ} \mathrm{C}$ ). Because the self-assembly of several proteins including actin, tubulin, and Fts $\mathrm{Z}$ is known to be enhanced by $\mathrm{D}_{2} \mathrm{O}$ relative to $\mathrm{H}_{2} \mathrm{O},{ }^{40}$ we also studied the polymerization of Mj-FtsZ induced by mantGTP in the Tris- $\mathrm{D}_{2} \mathrm{O}$ buffer used for NMR experiments, with additional $10 \mathrm{mM} \mathrm{MgCl}_{2}$. Thermophilic Mj-FtsZ did not polymerize at $25{ }^{\circ} \mathrm{C}$ with GTP in the $\mathrm{H}_{2} \mathrm{O}$ buffer nor in the Tris- $\mathrm{D}_{2} \mathrm{O}$ buffer (Figure 5A). However, mant-GTP strikingly induced nucleated polymerization of $\mathrm{Mj}$-FtsZ at $25{ }^{\circ} \mathrm{C}$ in Tris$\mathrm{D}_{2} \mathrm{O}$ buffer with $\mathrm{MgCl}_{2}$, with a $C_{\mathrm{r}} 4.0 \pm 0.5 \mu \mathrm{M}$ (Figure $5 \mathrm{~A}$ ). Polymerization at $55^{\circ} \mathrm{C}$ in $\mathrm{D}_{2} \mathrm{O}$ was also enhanced by the mant 

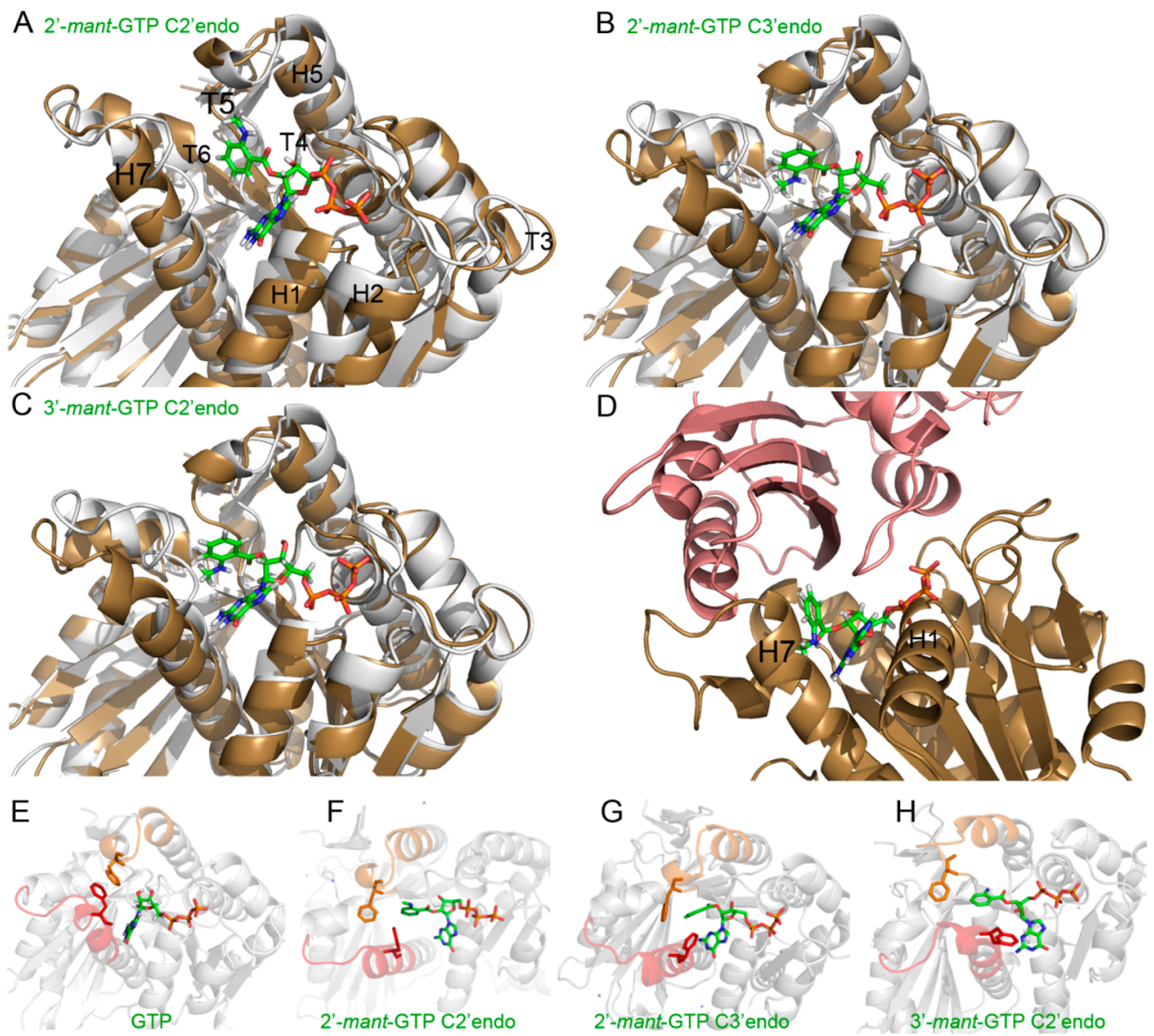

Figure 4. FtsZ-mant-GTP model complexes from MD simulations. (A) $2^{\prime}$-mant-GTP in the C2' endo conformation (green; observed during $60 \%$ of the $20 \mathrm{~ns} \mathrm{MD}$ trajectory) bound to a Mj-FtsZ monomer (sand color), superposed with Mj-FtsZ (gray). (B) Same as A but for $2^{\prime}$-mant-GTP in the C3' endo conformation (10\% of the MD duration). (C) $3^{\prime}$-mant-GTP in the $\mathrm{C} 2$ ' endo conformation ( $95 \%$ of the MD duration). These model structures observed during MD simulations (SI Movies M1-M3) are compatible with the tr-NOESY (Figure 2) and STD-NMR results (Figure 3). See also Figure S5. Detailed views of the mant-GTP interacting residues are depicted in Figure S6. (D) A different model of a Bacillus subtilis FtsZ dimer showing the association interface between two monomers (sand and salmon colored) with $2^{\prime}$-mant-3'-endo-GTP bound, in a rotated view with respect to A-C. The mant-nucleotide fits without steric clashes at the model interface; similar results were obtained with the $2^{\prime}$-mant-2'-endo and the 3-mant-2'-endo configurations. (E) Face to face $\pi$-stacking between Phe 208 (red) and Phe 162 (orange) in Mj-FtsZ with bound GTP, following MD (an egde to face $\pi$-stacking is observed in the crystal structure of Mj-FtsZ and also in FtsZ monomers from other species). (F) MjFtsZ with bound 2'-mant-GTP C3' endo. (G) Mj-FtsZ with bound 2'-mant-GTP C3' endo. (H) Mj-FtsZ with bound 3'-mant-GTP C2' endo. Note that the mant group breaks the Phe residues stacking in each case. The images were rendered using PyMOL.

substituent, proceeding with $C_{\mathrm{r}}$ values of $0.5 \pm 0.1 \mu \mathrm{M}$ (mantGTP), $2.2 \pm 0.5 \mu \mathrm{M}$ (GTP) and $2.4 \pm 0.2 \mu \mathrm{M}$ (apo-FtsZ; Figure 5B).

From these results, we first hypothesized that the additional interactions provided by the mant group at the interfacial GTPbinding site between $\mathrm{Mj}$-FtsZ monomers may favor polymerization. However, drastic structural differences in the formed polymers were found. The mant-GTP-induced $\mathrm{Mj}$-FtsZ polymers are curved spiral-like thin filaments at 25 or $55{ }^{\circ} \mathrm{C}$ (Figure 5C,D), considerably different from the straight filament bundles formed with GTP or the bundles observed without added nucleotide (Figure 5E,F). These observations correct our previous report of a similar morphology for mant-GTP and GTP-induced Mj-FtsZ polymers. ${ }^{26}$ The addition of GTP in excess over mant-GTP restored the straight polymer morphology, indicating that the mant-GTP effect is specific to the nucleotide-binding site. The mant-GTP-induced polymers are actually similar to the helically curved polymers of inactive $\mathrm{Mj}$ FtsZ with GDP, ${ }^{41}$ or with the C8-morpholino-GTP inhibitor ${ }^{29}$ or those observed for curved GTPase-inactive mutants of the Mj-FtsZ assembly switch. ${ }^{42}$ Therefore, we can reasonably conclude that mant-GTP behaves as a nucleotide inhibitor that induces abnormal polymerization of Mj-FtsZ into curved polymers with a defective GTPase site between subunits, which are characteristic of the assembly inactive forms of this protein; thus, these polymers are expected to have impaired dynamics. The filament curvature possibly prevents the cocatalytic loop T7 residues Asp235/Asp238 of the upper subunit $^{39}$ from approaching bound GTP for hydrolysis. Remarkably, a similar curved polymer phenotype is induced by different GTP analogs or GDP and even by the allosteric effects of mutations at the cleft between FtsZ domains. This observation suggests that a nonfunctional polymerization product of archaeal $\mathrm{Mj}$-FtsZ is formed in each case, possibly entailing a closed-cleft inactive conformation of FtsZ making weaker contacts with the neighbor subunits in the filament. ${ }^{42,43}$

Mant-GTP Behaves As a Substrate or Inhibitor for Different Bacterial FtsZ's. Next, the polymerization study was extended from the archaeal protein to FtsZs from model Gram-positive (Bs-FtsZ from Bacillus subtilis) and Gramnegative (Ec-FtsZ from Escherichia coli) bacteria. Bs-FtsZ assembles with mant-GTP with a higher $\operatorname{Cr}(5.6 \pm 0.3 \mu \mathrm{M})$ 


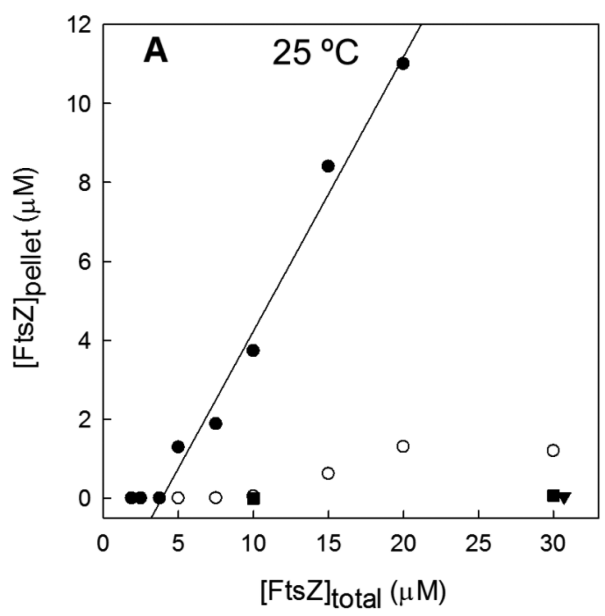

mant-GTP

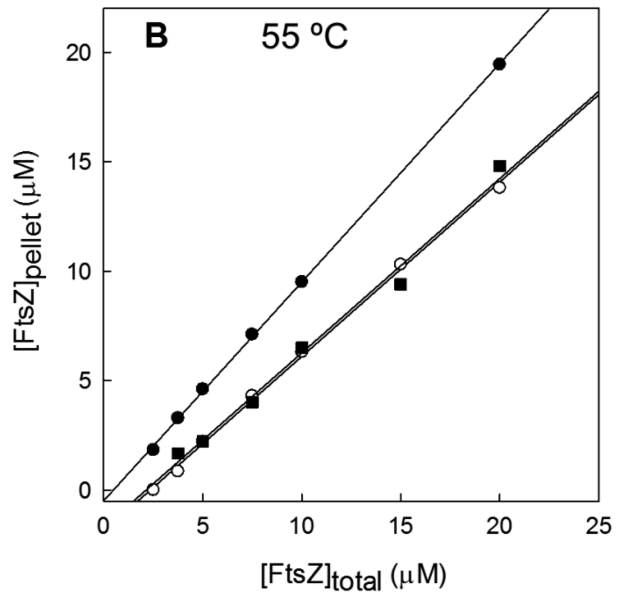

GTP

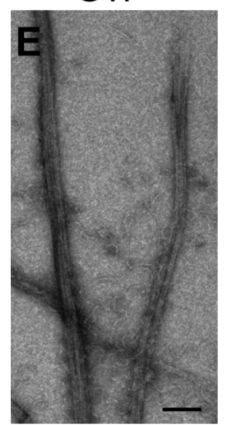

no nucl.

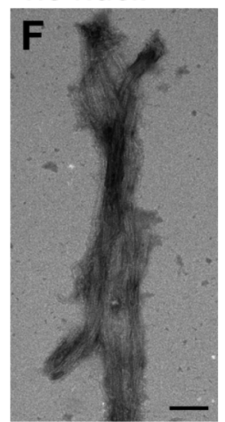

Figure 5. Polymerization of archaeal FtsZ with mant-GTP compared to GTP. (A) Sedimentation measurements of Mj-FtsZ polymers formed in Tris- $\mathrm{D}_{2} \mathrm{O}$ buffer at $25^{\circ} \mathrm{C}$ in the presence of $10 \mathrm{mM} \mathrm{MgCl}_{2}$, without nucleotide (O), with $50 \mu \mathrm{M}$ mant-GTP $(\bullet)$, with $1 \mathrm{mM}$ GTP (घ), or with 50 $\mu \mathrm{M}$ mant-GTP without magnesium as a control $(\boldsymbol{\nabla})$. Results from representative experiments are shown; a $C_{\mathrm{r}}$ of $4.0 \pm 0.5 \mu \mathrm{M}$ (value \pm standard error) was calculated as the intercept with the $x$ axis of a fit to the linear part the mant-GTP data, indicated by the solid line. (B) Same as A but at 55 ${ }^{\circ} \mathrm{C}$. Panels $\mathrm{C}-\mathrm{E}$ are representative electron micrographs of the negatively stained $\mathrm{Mj}$-FtsZ polymers formed with mant-GTP and GTP. (C) $10 \mu \mathrm{M}$ FtsZ with $100 \mu \mathrm{M}$ mant-GTP and $10 \mathrm{mM} \mathrm{MgCl} 2$ in Mes- $\mathrm{H}_{2} \mathrm{O}$ buffer at $55^{\circ} \mathrm{C}$. (D) Same as C but in Tris- $\mathrm{D}_{2} \mathrm{O}$ buffer at $25^{\circ} \mathrm{C}$. (E) $12.5 \mu \mathrm{M}$ FtsZ with $1 \mathrm{mM}$ GTP and $10 \mathrm{mM} \mathrm{MgCl}_{2}$ in Tris- $\mathrm{D}_{2} \mathrm{O}$ buffer at $55^{\circ} \mathrm{C}$. Images similar to E were obtained in $\mathrm{Mes}^{\circ} \mathrm{H}_{2} \mathrm{O}$ buffer with $10 \mathrm{mM} \mathrm{MgCl}_{2}$ at $55{ }^{\circ} \mathrm{C}$ with $2 \mathrm{mM}$ GTP or with $200 \mu \mathrm{M}$ mant-GTP plus $2 \mathrm{mM}$ GTP. (F) Same as E minus nucleotide. Bars are $100 \mathrm{~nm}$.

than with GTP $(\mathrm{Cr}=2.8 \pm 0.4 \mu \mathrm{M})$, forming filaments with a similar morphology, although less bundled (Figure 6A). BsFtsZ hydrolyzes mant-GTP (mant-GTPase rate $0.11 \pm 0.01$ $\mathrm{min}^{-1}$ ), although more slowly than GTP (GTPase rate $0.60 \pm$ $0.08 \mathrm{~min}^{-1}$ ). Thus, we can conclude that, strikingly, mant-GTP is an assembly inducer and a slow substrate for Bs-FtsZ, rather than an inhibitor.

In contrast, Ec-FtsZ with mant-GTP forms short curved filaments and mini-rings that can be observed in open or completely closed shapes and do not sediment as the FtsZGTP polymer in the assay (Figure 6B; pellet inhibition by mant-GTP was reversed by GTP). Ec-FtsZ exhibits markedly reduced mant-GTPase activity (mant-GTPase rate, $0.08 \pm 0.01$ $\min ^{-1}$; GTPase rate, $\left.1.09 \pm 0.06 \mathrm{~min}^{-1}\right)$. This observation is compatible with a disruption of the proper longitudinal contact for GTPase activation in the curved association mode. Thus, mant-GTP behaves as a specific assembly inhibitor of Ec-FtsZ. We note that the mini-rings $(21 \pm 3 \mathrm{~nm}$ in diameter $)$ resemble those formed with Ec-FtsZ-GDP on a polycationic lipid monolayer $^{44}$ and also those mini-rings that we have observed during depolymerization of Ec-FtsZ at high concentrations (S. Huecas, unpublished results).

The markedly different effects of mant-GTP on the assembly of Mj-FtsZ (a non hydrolyzable inhibitor), Bs-FtsZ (a slow substrate), and Ec-FtsZ (an inhibitor) are possibly related to the different assembly interfaces among archaeal and bacterial FtsZs that have been probed with C8-GTP analogs ${ }^{29}$ and synthetic inhibitors. ${ }^{30}$ Nevertheless, the high structural similarity of the nucleotide binding site of FtsZ monomers from divergent organisms, ${ }^{45}$ as well as the similar binding affinities of nucleotide analogs ${ }^{29}$ and synthetic competitors ${ }^{30}$ to archaeal and bacterial FtsZ monomers, support the use of $\mathrm{Mj}$ FtsZ as a model for the conserved nucleotide binding site of FtsZ monomers. Among other GTP binding proteins, the inhibition of membrane adenylyl cyclase by mant-GTP is explained by binding of the mant fluorophore within a hydrophobic pocket between protein domains. ${ }^{7}$ On the other hand, the unaffected microtubule assembly with mant-GTP ${ }^{10}$ indicates the possibility of selective inhibition of bacterial FtsZ rather than the eukaryotic homologue tubulin. The additional interactions between the mant tag and the GTP binding site of FtsZ thus provide clues for the design of new GTP-replacing ligands and FtsZ assembly modulators endowed with antibacterial activity.

Conclusions. FtsZ is a self-assembling GTPase that organizes cell division in most bacteria and is also an attractive target for new antibiotics. We have unraveled the molecular recognition process of the widely used fluorescent nucleotide $2^{\prime} / 3^{\prime}$ mant-GTP by the cell division protein FtsZ, at different levels. tr-NOESY-NMR indicates that FtsZ specifically binds 
A Bs-FtsZ

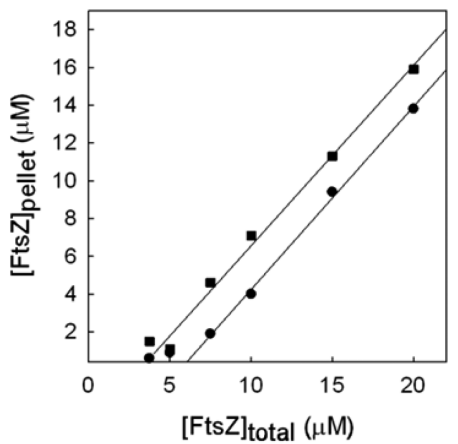

B Ec-FtsZ

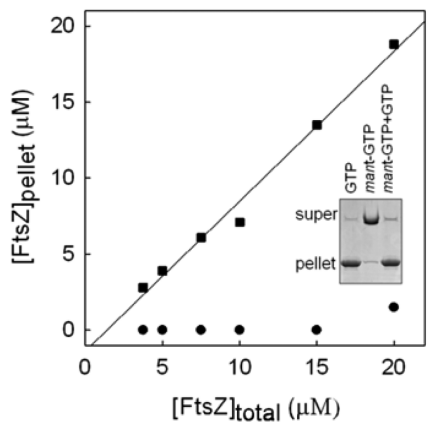

GTP

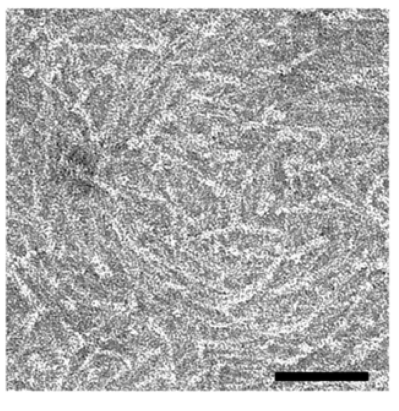

GTP

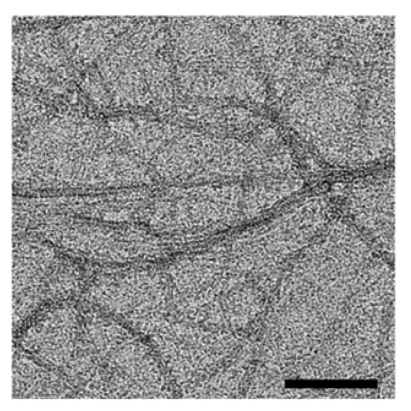

mant-GTP

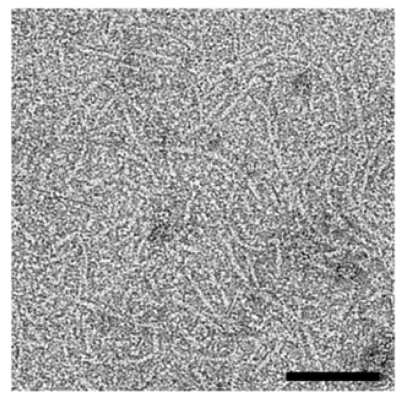

mant-GTP

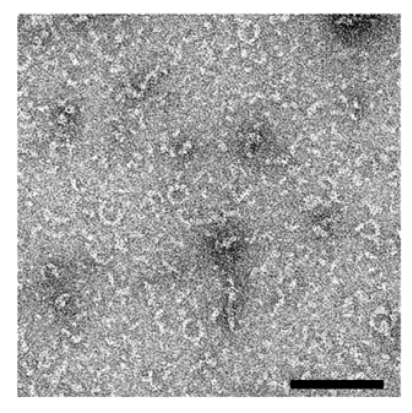

Figure 6. Polymerization of bacterial FtsZs with mant-GTP and GTP. (A) Polymerization of Bs-FtsZ measured by sedimentation in Mes buffer at $\mathrm{pH} 6.5$ in the presence of $10 \mathrm{mM} \mathrm{MgCl}$ and $1 \mathrm{mM} \mathrm{GTP}(\mathbf{\square})$ or $1 \mathrm{mM}$ mant-GTP $(\mathbf{O})$, and electron micrographs of negatively stained polymers formed under identical conditions with $10 \mu \mathrm{M}$ FtsZ. Assembly was not observed without nucleotides. Bars indicate $100 \mathrm{~nm}$. (B) Similar experiments performed with Ec-FtsZ. The inset in the left panel shows a polymer pelleting assay of $10 \mu \mathrm{M} \mathrm{Ec-FtsZ} \mathrm{with} 5 \mathrm{mM}$ GTP, $1 \mathrm{mM}$ mant-GTP, or both 1 $\mathrm{mM}$ mant-GTP and $5 \mathrm{mM}$ GTP. The mant-GTP effect on polymer morphology was reversed by GTP.

mant-GTP in the anti glycosidic bond conformation as for GTP. Both the $2^{\prime}$-mant-GTP isomer (in two distinct ribose puckering conformations) and the $3^{\prime}$-mant-GTP isomer (only the preferred $\mathrm{C}^{\prime}$ endo conformer) can bind, underscoring the plasticity of the FtsZ nucleotide binding site. STD-NMR indicates that the aromatic mant ring participates in substantial interactions with FtsZ. This observation is also supported by MD simulations of FtsZ-mant-GTP complexes that reveal an extension of the conserved GTP-binding site of FtsZ monomers. Because the nucleotide binding site becomes part of the longitudinal association interface between monomers for assembly into functional FtsZ filaments, the introduction of the $2^{\prime}$ - or $3^{\prime}$-mant groups attached to the nucleotide ribose remodels the association interface between the FtsZ monomers, disrupting normal assembly. Indeed, mant-GTP binding to archaeal Mj-FtsZ induces polymerization into curved inactive filaments that no longer hydrolyze the nucleotide and also inhibits the assembly of the Gram-negative bacterial Ec-FtsZ. In contrast, mant-GTP is a substrate for the Gram-positive BsFtsZ. These observations support the existence of different assembly interfaces among FtsZ proteins. We propose that the additional interactions provided by the fluorescent mant tag at the extended GTP-binding site may be exploited for the design of high affinity synthetic inhibitors of FtsZ that can suppress cell division of bacterial pathogens.

\section{METHODS}

Nucleotides, FtsZ Proteins and Biochemical Methods. mantGTP (triethylammonium salt solution) was obtained from Jena Bioscience. Prior to the NMR experiments, mant-GTP was lyophilized and dissolved in $99.9 \% \mathrm{D}_{2} \mathrm{O}$ (Cambridge Isotope Laboratories) to a concentration of $50 \mathrm{mM}$. GTP (lithium salt) was from Sigma. FtsZ from M. jannaschii (Mj-FtsZ) was overexpressed in E. coli BL21(DE3) pLyS cells, purified, and depleted of nucleotide (apo-FtsZ) as previously described. ${ }^{41}$ For NMR experiments and their biochemical controls, Mj-FtsZ was equilibrated in $25 \mathrm{mM} \mathrm{d} \mathrm{d}_{11}$-Tris-DCl, $50 \mathrm{mM}$ $\mathrm{KCl}$, and $1 \mathrm{mM}$ EDTA dissolved in $99.9 \% \mathrm{D}_{2} \mathrm{O}$, with an uncorrected $\mathrm{pH}$ of 7.4 (Tris- $\mathrm{D}_{2} \mathrm{O}$ buffer), using an HR 10/10 Fast Desalting Column (Pharmacia Biotech), and then concentrated with a $\mathrm{D}_{2} \mathrm{O}$ prewashed Centricon YM10 (Millipore) filter at $4{ }^{\circ} \mathrm{C}$. The concentration of apo-FtsZ was determined spectrophotometrically using an extinction coefficient $\varepsilon_{280}=6990 \mathrm{M}^{-1} \mathrm{~cm}^{-1}$. FtsZ from $B$. subtilis (Bs-FtsZ) was overexpressed in E. coli C41(DE3) cells and purified as described, with $\sim 0.05$ guanine nucleotide bound per FtsZ. ${ }^{30}$ FtsZ from E. coli (Ec-FtsZ) was overproduced in transformed E. coli BL21(DE3) cells and purified using a $\mathrm{Ca}^{2+}$-precipitation and anion-exchange method, with $\sim 0.8$ guanine nucleotide bound. ${ }^{46}$ Experiments in $\mathrm{H}_{2} \mathrm{O}$ were performed in $50 \mathrm{mM}$ Mes- $\mathrm{KOH}, 50 \mathrm{mM}$ $\mathrm{KCl}, 1 \mathrm{mM}$ EDTA, $10 \mathrm{mM} \mathrm{MgCl}$, at $\mathrm{pH} 6.5$ (Mes buffer), except as indicated otherwise. Mant-GTP $(50 \mathrm{nM})$ was titrated with increasing concentrations of apo-FtsZ in Tris- $\mathrm{D}_{2} \mathrm{O}$ buffer and compared to similar titrations in $25 \mathrm{mM}$ Tris- $\mathrm{HCl}, 50 \mathrm{mM} \mathrm{KCl}, 1 \mathrm{mM}$ EDTA in $\mathrm{H}_{2} \mathrm{O}$, at $\mathrm{pH} 7.4$, both with $10 \mathrm{mM} \mathrm{MgCl}_{2}$ and at $25^{\circ} \mathrm{C}$. Anisotropy measurements, and the calculation of free and bound fluorophore and binding constants were performed as previously described. ${ }^{27,30}$ Negative stain electron microscopy of FtsZ polymers was performed as previously described. ${ }^{29}$ Hydrolysis of GTP or mant-GTP (1 mM) by FtsZ $(10 \mu \mathrm{M})$ was measured from the released inorganic phosphate in Mes buffer, at $25{ }^{\circ} \mathrm{C}$ for Ec- and Bs-FtsZ and at $55^{\circ} \mathrm{C}$ for Mj-FtsZ, and FtsZ polymers were quantified by isothermal pelleting and protein concentration measurement. ${ }^{30}$

Association State of Mj-FtsZ under NMR Solution Conditions. Unassembled Mj-FtsZ is known to form oligomers in a nonspecific, magnesium and nucleotide insensitive manner that is unrelated to polymerization. Mj-FtsZ is monomeric only at submicromolar concentrations below the NMR sensitivity. We thus analyzed the Mj-FtsZ association state in Tris- $\mathrm{D}_{2} \mathrm{O}$ buffer with 
sedimentation velocity measurements in an analytical ultracentrifuge as previously described. ${ }^{29}$ The sedimentation coefficient distribution of FtsZ $(30 \mu \mathrm{M})$ was not significantly modified by mant-GTP $(0.6 \mathrm{mM})$ compared to GTP $(1.2 \mathrm{mM})$, showing in both cases a main $(82-87 \%)$ $s_{20, \mathrm{w}}=5.8 \mathrm{~S}$ sedimentation boundary compatible with FtsZ dimers and smaller proportions of $s_{20, \mathrm{w}}=3.8 \mathrm{~S}$ FtsZ monomers $(8-14 \%)$ and $s_{20, \mathrm{w}}$ $\approx 8.6 \mathrm{~S}$ tetramers $(2-4 \%)$ (Figure $\mathrm{S} 3 \mathrm{~B}$ ). These results indicated that the mant nucleotide does not participate in the limited $\mathrm{Mj}$-FtsZ oligomerization, permitting NMR analysis of mant-GTP binding to the GTP binding site without potential interference from changes in protein association.

NMR Experiments. NMR spectra were recorded on a Bruker AVANCE $600 \mathrm{MHz}$ spectrometer equipped with a triple channel cryoprobe. Free mant-GTP was diluted to $1 \mathrm{mM}$ in Tris- $\mathrm{D}_{2} \mathrm{O}$ buffer. The coupling constants were obtained from the splitting measured in the ${ }^{1} \mathrm{H}$ NMR spectrum. NMR assignments were based on coupling constants, assisted by standard 2D-TOCSY (20 and $60 \mathrm{~ms})$ and 2DNOESY experiments. The NOESY cross-peaks were essentially zero at $298 \mathrm{~K}$; therefore 2D-NOESY experiments (500 and $700 \mathrm{~ms}$ mixing times) were recorded at $313 \mathrm{~K}$, where the NOEs are moderately positive. For the binding studies, Mj-FtsZ $(30 \mu \mathrm{M})$ was equilibrated in the same Tris- $\mathrm{D}_{2} \mathrm{O}$ buffer (without $\mathrm{MgCl}_{2}$, to avoid FtsZ polymerization). 2D TR-NOESY experiments were recorded using mixing times of 100 and $200 \mathrm{~ms}$ at $298 \mathrm{~K}$, with a $20: 1$ nucleotide/protein molar ratio. No purging spin-lock period was employed to remove the NMR signals of the macromolecule background. STD-NMR experiments were performed with 20:1 nucleotide/protein molar ratios at 298 K. A series of Gaussian-shaped pulses of $49 \mathrm{~ms}$ each were applied, separated by $1 \mathrm{~ms}$ delay, with a total saturation time for the protein envelope of $2 \mathrm{~s}$ and a maximum B1 field strength of $50 \mathrm{~Hz}$. The offresonance frequency was set at $\delta=100 \mathrm{ppm}$ (at which no proteins signals are present) while the on-resonance frequency was applied at $\delta$ $=0 \mathrm{ppm}$. The spectra were multiplied by an exponential linebroadening function of $1 \mathrm{~Hz}$ prior to Fourier transformation. A $15 \mathrm{~ms}$ spin lock pulse was applied to minimize the background protein resonances. To obtain epitope maps of mant-GTP isomers, the STD intensities were normalized with respect to that of the highest response.

Conformational Analysis of Free $2^{\prime}$ - and $3^{\prime}$-mant-GTP. Molecular mechanics calculations were performed using MacroModel 9.6 (Schrödinger, LLC, New York) as previously described. ${ }^{29}$ The 3D structures of $2^{\prime}$ - and $3^{\prime}$-mant-GTP were built using $\mathrm{C} 2^{\prime}$ endo (Protein Data Bank (PDB) entry: 1a8r) and $\mathrm{C}^{\prime}$ endo (PBD entry: 1tvk) conformations of the furanose ring of GTP as starting geometries. The syn-anti conformational equilibrium for each furanose puckering was analyzed with a coordinate scan around the glycosidic torsion angle $(\chi$, defined as $\left.\mathrm{H1}^{\prime}-\mathrm{Cl}^{\prime}-\mathrm{N} 9-\mathrm{C} 8\right)$. We also performed a coordinate scan combining the $\chi$ angle and the $\mathrm{CO}-\mathrm{O}-\mathrm{C} 2-\mathrm{H} 2$ or $\mathrm{CO}-\mathrm{O}-\mathrm{C} 3-\mathrm{H} 3$ angles for 2 -mant-GTP or 3 '-mant-GTP, respectively. All the calculated structures were then analyzed in terms of their potential energies. The $J_{1^{\prime}, 2^{\prime}}$ and $J_{3^{\prime}, 4^{\prime}}$ coupling constants for both isomers were calculated from the ensemble averaged torsion angles and for the corresponding local minima using the empirical generalization of the Karplus equation ${ }^{47}$ and were compared to the experimental coupling constants. Additionally, selected interproton distances, $\mathrm{H} 8-\mathrm{H1} 1^{\prime}, \mathrm{H} 8-$ $\mathrm{H} 2^{\prime}$, and $\mathrm{H} 8-\mathrm{H}^{\prime}$ and those between ribose protons and the fluorescent aromatic tag, were also measured and compared to the corresponding NOE experimental data. The conformations that better explain the experimental data in solution were further minimized using OPLS* as a force field, ${ }^{48}$ where the bulk-water solvation was simulated by using the generalized Born/surface area (GB/SA) continuum solvent model. ${ }^{49}$ The general PRCG (Polak-Ribiere Conjugate Gradient) method for energy minimization was employed.

Molecular Dynamics Simulations of FtsZ-mant-GTP Complexes. $\mathrm{MD}$ simulations in water and counterions, $0.15 \mathrm{M} \mathrm{NaCl}$ at $\mathrm{pH}$ 7.4 and $300 \mathrm{~K}$, were performed with the AMBER 11 package ${ }^{50}$ as previously described. ${ }^{29}$ The 2'- and 3'-mant-GTP structures were obtained by substitution of $\mathrm{H}^{\prime}{ }^{\prime}$ or $\mathrm{H}^{\prime}$ ' ribose protons respectively for the mant group in GTP (from the PDB entry 1w5a, chain A). Representative structures for each conformer were obtained from $4 \mathrm{~ns}$
$\mathrm{MD}$ simulations of the ligand alone, taking an averaged structure from the last $0.5 \mathrm{~ns}$, when it is stabilized. The initial structures of $\mathrm{Mj}$-FtsZ in complex with $2^{\prime}$ - and $3^{\prime}$ - mant-GTP-Mg ${ }^{2+}$ were obtained by exchanging GTP (PDB 1w5a) with the $2^{\prime}$ - and $3^{\prime}$ - mant-GTP conformers. These models were then energy minimized, equilibrated, and subjected to 20 ns MD simulations. The Bs-FtsZ structure (PDB 2vxy) was modeled onto the Staphylococcus aureus FtsZ filament structure (PDB 3vo8), and Bs-FtsZ dimer complexes with $2^{\prime}$ - and $3^{\prime}$-mant-GTP- $\mathrm{Mg}^{2+}$ were obtained by exchanging the nucleotide as described above, followed by energy minimization.

\section{ASSOCIATED CONTENT}

\section{S Supporting Information}

The Supporting Information is available free of charge on the ACS Publications website at DOI: 10.1021/acschembio.5b00444.
Figures S1-S6 (PDF)
MD Movie M1 (MPG)
MD Movie M2 (MPG)
MD Movie M3 (MPG)

\section{AUTHOR INFORMATION}

\section{Corresponding Authors}

*E-mail: jjbarbero@cicbiogune.es.

*E-mail: j.m.andreu@cib.csic.es

\section{Present Addresses}

${ }^{\perp}$ Smartligs, Faraday 7, Cantoblanco, 29049 Madrid, Spain

${ }^{\#}$ Chromosome Organization and Dynamics, Max Planck Institute of Biochemistry, Am Klopferspitz 18, 82152 Martinsried, Germany

${ }^{\nabla}$ Repsol, Technology Centre, Móstoles, 28923 Madrid, Spain

${ }^{\circ}$ CIC bioGUNE Parque Tecnológico de Bizkaia, Edif. 801A- ${ }^{\circ}$, 48160 Derio-Bizkaia, Spain \& Ikerbasque, Basque Foundation for Science, 48031 Bilbao, Spain

\section{Author Contributions}

"S.H. and F.M. contributed equally to the work

Notes

The authors declare no competing financial interest.

\section{ACKNOWLEDGMENTS}

We thank D. Juan (CIB-CSIC) for proteins purification. This work was supported by grants BFU2011-23416 and BFU201451823-R (J.M.A), CTQ2012-32065 (J.J.B.), CM 2010/BMD2353 (J.J.B. and J.M.A.), FCT SFRH/BPD/65462/2009 and UID/Multi/04378/2013 (F.M.) and a FPI fellowship (L.B.R.A).

\section{REFERENCES}

(1) Metzker, M. L. (2010) Sequencing technologies - the next generation. Nat. Rev. Genet. 11, 31-46.

(2) Hiratsuka, T. (1983) New ribose-modified fluorescent analogs of adenine and guanine nucleotides available as substrates for various enzymes. Biochim. Biophys. Acta, Protein Struct. Mol. Enzymol. 742, 496-500.

(3) Jameson, D. M., and Eccleston, J. F. (1997) Fluorescent nucleotide analogs: Synthesis and applications. Methods Enzymol. 278, 363-390.

(4) Neal, S. E., Eccleston, J. F., and Webb, M. R. (1990) Hydrolysis of GTP by p21NRAS, the NRAS protooncogene product, is accompaniued by a conformational change in the wild-tytpe protein: Use of a single fluorescent probe at the catalytic site. Proc. Natl. Acad. Sci. U. S. A. 87, 3562-3565. 
(5) Remmers, A. E., Posner, R., and Neubig, R. R. (1994) Fluorescent guanine-nucelotide analogs and G-protein activation. J. Biol. Chem. 269, 13771-13778.

(6) Newton, M., Niewczas, I., Clark, J., and Bellamy, T. C. (2010) A real-time fluorescent assay of the purified nitric oxide receptor, guanylyl cyclase. Anal. Biochem. 402, 129-136.

(7) Mou, T. C., Gille, A., Fancy, D. A., Seifert, R., and Sprang, S. R. (2005) Structural basis for the inhibition of mammalian membrane adenylyl cyclase by 2 '( 3 ')-O-(N-methylanthraniloyl)-guanosine 5 '-triphosphate. J. Biol. Chem. 280, 7253-7261.

(8) Mou, T. C., Gille, A., Suryanarayana, S., Richter, M., Seifert, R., and Sprang, S. R. (2006) Broad specificity of mammalian adenylyl cyclase for interaction with 2 ', 3 '-substituted purine- and pyrimidine nucleotide inhibitors. Mol. Pharmacol. 70, 878-886.

(9) Mazhab-Jafari, M. T., Marshall, C. B., Smith, M., Gasmi-Seabrook, G. M. C., Stambolic, V., Rottapel, R., Neel, B. G., and Ikura, M. (2010) Real-time NMR Study of Three Small GTPases Reveals That Fluorescent 2 '( 3 ')-O-(N-Methylanthraniloyl)-tagged Nucleotides Alter Hydrolysis and Exchange Kinetics. J. Biol. Chem. 285, 51325136.

(10) Muraoka, M., Fukuzawa, H., Nishida, A., Okano, K., Tsuchihara, T., Shimoda, A., Suzuki, Y., Sato, M., Osumi, M., and Sakai, H. (1999) The effects of various GTP analogues on microtubule assembly. Cell Struct. Funct. 24, 101-109.

(11) Scheidig, A. J., Franken, S. M., Corrie, J. E. T., Reid, G. P., Wittinghofer, A., Pai, E. F., and Goody, R. S. (1995) X-ray crystal structure analysis of the catalytic domain of the oncogene product p21(H-RAS) complexed with caged GTP and mant DGPPNHP. J. Mol. Biol. 253, 132-150.

(12) Groves, P., Strzelecka-Kiliszek, A., Sekrecka-Belniak, A., Canales, A., Jimenez-Barbero, J., Bandorowicz-Pikula, J., Pikula, S., and Canada, F. J. (2013) Exploring NMR methods as a tool to select suitable fluorescent nucleotide analogues. Org. Biomol. Chem. 11, 5332-5338.

(13) Lutkenhaus, J., Pichoff, S., and Du, S. S. (2012) Bacterial cytokinesis: From $\mathrm{Z}$ ring to divisome. Cytoskeleton 69, 778-790.

(14) Meier, E. L., and Goley, E. D. (2014) Form and function of the bacterial cytokinetic ring. Curr. Opin. Cell Biol. 26, 19-27.

(15) Nogales, E., Downing, K. H., Amos, L. A., and Lowe, J. (1998)

Tubulin and FtsZ form a distinct family of GTPases. Nat. Struct. Biol. $5,451-458$.

(16) Mitchison, T., and Kirschner, M. (1984) Dynamic instability of microtubule growth. Nature 312, 237-242.

(17) Loose, M., and Mitchison, T. J. (2014) The bacterial cell division proteins FtsA and FtsZ self-organize into dynamic cytoskeletal patterns. Nat. Cell Biol. 16, 38-46.

(18) Haydon, D. J., Stokes, N. R., Ure, R., Galbraith, G., Bennett, J. M., Brown, D. R., Baker, P. J., Barynin, V. V., Rice, D. W., Sedelnikova, S. E., Heal, J. R., Sheridan, J. M., Aiwale, S. T., Chauhan, P. K., Srivastava, A., Taneja, A., Collins, I., Errington, J., and Czaplewski, L. G. (2008) An inhibitor of FtsZ with potent and selective antistaphylococcal activity. Science 321, 1673-1675.

(19) Andreu, J. M., Schaffner-Barbero, C., Huecas, S., Alonso, D., Lopez-Rodriguez, M. L., Ruiz-Avila, L. B., Nunez-Ramirez, R., Llorca, O., and Martin-Galiano, A. J. (2010) The antibacterial cell division inhibitor PC190723 is a FtsZ polymer stabilizing agent which induces filament assembly and condensation. J. Biol. Chem. 285, 14239-14246.

(20) Elsen, N. L., Lu, J., Parthasarathy, G., Reid, J. C., Sharma, S., Soisson, S. M., and Lumb, K. J. (2012) Mechanism of Action of the Cell-Division Inhibitor PC190723: Modulation of FtsZ Assembly Cooperativity. J. Am. Chem. Soc. 134, 12342-12345.

(21) Plaza, A., Keffer, J. L., Bifulco, G., Lloyd, J. R., and Bewley, C. A. (2010) Chrysophaentins A-H, Antibacterial Bisdiarylbutene Macrocycles That Inhibit the Bacterial Cell Division Protein FtsZ. J. Am. Chem. Soc. 132, 9069-9077.

(22) Sass, P., Josten, M., Famulla, K., Schiffer, G., Sahl, H. G., Hamoen, L., and Brotz-Oesterhelt, H. (2012) Antibiotic acyldepsipeptides activate ClpP peptidase to degrade the cell division protein FtsZ. Proc. Natl. Acad. Sci. U. S. A. 108, 17474-17479.
(23) Schaffner-Barbero, C., Martin-Fontecha, M., Chacon, P., and Andreu, J. M. (2012) Targeting the Assembly of Bacterial Cell Division Protein FtsZ with Small Molecules. ACS Chem. Biol. 7, 268276.

(24) den Blaauwen, T., Andreu, J. M., and Monasterio, O. (2014) Bacterial cell division proteins as antibiotic targets. Bioorg. Chem. 55, $27-38$.

(25) Lewis, K. (2012) Antibiotics: Recover the lost art of drug discovery. Nature 485, 439-440.

(26) Huecas, S., Schaffner-Barbero, C., Garcia, W., Yebenes, H., Palacios, J. M., Diaz, J. F., Menendez, M., and Andreu, J. M. (2007) The interactions of cell division protein FtsZ with guanine nucleotides. J. Biol. Chem. 282, 37515-37528.

(27) Schaffner-Barbero, C., Gil-Redondo, R., Ruiz-Avila, L. B., Huecas, S., Lappchen, T., den Blaauwen, T., Diaz, J. F., Morreale, A., and Andreu, J. M. (2010) Insights into nucleotide recognition by cell division protein FtsZ from a mant-GTP competition assay and molecular dynamics. Biochemistry 49, 10458-10472.

(28) Läppchen, T., Pinas, V. A., Hartog, A. F., Koomen, G. J., Schaffner-Barbero, C., Andreu, J. M., Trambaiolo, D., Lowe, J., Juhem, A., Popov, A. V., and den Blaauwen, T. (2008) Probing FtsZ and tubulin with C8-substituted GTP analogs reveals differences in their nucleotide binding sites. Chem. Biol. 15, 189-199.

(29) Marcelo, F., Huecas, S., Ruiz-Avila, L. B., Canada, F. J., Perona, A., Poveda, A., Martin-Santamaria, S., Morreale, A., Jimenez-Barbero, J., and Andreu, J. M. (2013) Interactions of Bacterial Cell Division Protein FtsZ with C8-Substituted Guanine Nucleotide Inhibitors. A Combined NMR, Biochemical and Molecular Modeling Perspective. J. Am. Chem. Soc. 135, 16418-16428.

(30) Ruiz-Avila, L. B., Huecas, S., Artola, M., Vergonos, A., RamirezAportela, E., Cercenado, E., Barasoain, I., Vazquez-Villa, H., MartinFontecha, M., Chacon, P., Lopez-Rodriguez, M. L., and Andreu, J. M. (2013) Synthetic Inhibitors of Bacterial Cell Division Targeting the GTP-Binding Site of FtsZ. ACS Chem. Biol. 8, 2072-2083.

(31) Keffer, J. L., Huecas, S., Hammill, J. T., Wipf, P., Andreu, J. M., and Bewley, C. A. (2013) Chrysophaentins are competitive inhibitors of FtsZ and inhibit Z-ring formation in live bacteria. Bioorg. Med. Chem. 21, 5673-5678.

(32) Artola, M., Ruiz-Avila, L. B., Vergoñós, A., Huecas, S., AraujoBazán, L., Martín-Fontecha, M., Vázquez-Villa, H., Turrado, C., Ramírez-Aportela, E., Hoegl, A., Nodwell, A., Barasoain, I., Chacón, P., Sieber, S. A., Andreu, J. M., and M, L.-R. (2015) Effective GTPreplacing FtsZ Inhibitors and Antibacterial Mechanism of Action. ACS Chem. Biol. 10, 834-843.

(33) Sarma, R. H., Lee, C. H., Evans, F. E., Yathindra, N., and Sundaralingam, M. (1974) Probing interrelation between glycosyl torsion, sugar pucker, and backbone conformation in $\mathrm{C}(8)$ substituted adenine nucleotides by $\mathrm{H}-1$ and $\mathrm{H}-1-\mathrm{P}-31$ fast Fourier transform nuclear magnetic resonance methods and conformational energy calculations. J. Am. Chem. Soc. 96, 7337-7348.

(34) Rosemeyer, H., Toth, G., Golankiewicz, B., Kazimierczuk, Z., Bourgeois, W., Kretschmer, U., Muth, H. P., and Seela, F. (1990) Syn Anti-conformational analysis of regular and modified nucleosides by 1D H-1 NOE difference spectroscopy- A simple graphical method based on conformationally rigid molecules. J. Org. Chem. 55, 57845790.

(35) Meyer, B., and Peters, T. (2003) NMR Spectroscopy techniques for screening and identifying ligand binding to protein receptors. Angew. Chem., Int. Ed. 42, 864-890.

(36) Jimenez-Barbero, J., Canales, A., Northcote, P. T., Buey, R. M., Andreu, J. M., and Diaz, J. F. (2006) NMR determination of the bioactive conformation of peloruside a bound to microtubules. J. Am. Chem. Soc. 128, 8757-8765.

(37) Wang, Y. S., Liu, D. J., and Wyss, D. F. (2004) Competition STD NMR for the detection of high-affinity ligands and NMR-based screening. Magn. Reson. Chem. 42, 485-489.

(38) Ribeiro, J. P., Andre, S., Canada, F. J., Gabius, H. J., Butera, A. P., Alves, R. J., and Jimenez-Barbero, J. (2010) Lectin-Based Drug Design: Combined Strategy to Identify Lead Compounds using STD NMR 
Spectroscopy, Solid-Phase Assays and Cell Binding for a Plant Toxin Model. ChemMedChem 5, 415-419.

(39) Oliva, M. A., Cordell, S. C., and Lowe, J. (2004) Structural insights into FtsZ protofilament formation. Nat. Struct. Mol. Biol. 11, $1243-1250$.

(40) Santra, M. K., Dasgupta, D., and Panda, D. (2005) Deuterium oxide promotes assembly and bundling of FtsZ protofilaments. Proteins: Struct., Funct., Genet. 61, 1101-1110.

(41) Huecas, S., and Andreu, J. M. (2004) Polymerization of nucleotide-free, GDP- and GTP-bound cell division protein FtsZ: GDP makes the difference. FEBS Lett. 569, 43-48.

(42) Martín-Galiano, A. J., Buey, R. M., Cabezas, M., and Andreu, J. M. (2010) Mapping Flexibility and the Assembly Switch of Cell Division Protein FtsZ by Computational and Mutational Approaches. J. Biol. Chem. 285, 22554-22565.

(43) Ramirez-Aportela, E., Lopez-Blanco, J. R., Andreu, J. M., and Chacon, P. (2014) Understanding Nucleotide-Regulated FtsZ Filament Dynamics and the Monomer Assembly Switch with LargeScale Atomistic Simulations. Biophys. J. 107, 2164-2176.

(44) Erickson, H. P., Taylor, D. W., Taylor, K. A., and Bramhill, D. (1996) Bacterial cell division protein FtsZ assembles into protofilament sheets and minirings, structural homologs of tubulin polymers. Proc. Natl. Acad. Sci. U. S. A. 93, 519-523.

(45) Oliva, M. A., Trambaiolo, D., and Lowe, J. (2007) Structural insights into the conformational variability of FtsZ. J. Mol. Biol. 373, 1229-1242.

(46) Rivas, G., Lopez, A., Mingorance, J., Ferrandiz, M. J., Zorrilla, S., Minton, A. P., Vicente, M., and Andreu, J. M. (2000) Magnesiuminduced linear self-association of the FtsZ bacterial cell division protein monomer - The primary steps for FtsZ assembly. J. Biol. Chem. 275, $11740-11749$.

(47) Haasnoot, C. A. G., Deleeuw, F. A. A. M., and Altona, C. (1980) The relationship between proton-proton NMR coupling constants and substituent electronegativities-I: An empirical generalization of the karplus equation. Tetrahedron 36, 2783-2792.

(48) Jorgensen, W. L., Maxwell, D. S., and Tirado-Rives, J. (1996) Development and Testing of the OPLS All-Atom Force Field on Conformational Energetics and Properties of Organic Liquids. J. Am. Chem. Soc. 118, 11225-11236.

(49) Still, W. C., Tempczyk, A., Hawlely, R. C., and Hendrickson, T. A. (1990) General treatment of solvation for molecular mechanics. J. Am. Chem. Soc. 112, 6127-6129.

(50) Case, D. A.; Darden, T. A.; Cheatham, T. E.; Simmerling, C. L.; Wang, J.; Duke, R. E.; Luo, R.; Walker, R. C.; Zhang, W.; Merz, K. M.; Roberts, B.; Wang, B.; Hayik, S.; Roitberg, A.; Seabra, G.; Kolossváry, I., Wong, K. F.; Paesani, F.; Vanicek, J.; Liu, J.; Brozell, S. R.; Steinbrecher, T.; Gohlke, H.; Cai, Q.; Ye, X.; Wang, J.; Hsieh, M.-J.; Cui, G.; Roe, D. R.; Mathews, D. H.; Seetin, M. G.; Sagui, C.; Babin, V.; Luchko, T.; Gusarov, S.; Kovalenko, A. and Kollman, P. A. (2010) AMBER 11, University of California, San Francisco. 